\title{
Corrigendum: The Unknown and the Unexplored: Insights Into the Pacific Deep-Sea Following NOAA CAPSTONE Expeditions
}

\section{OPEN ACCESS}

Edited by:

Cinzia Corinaldesi,

Marche Polytechnic University, Italy

Reviewed by:

Pedro A. Ribeiro,

University of Bergen, Norway

*Correspondence:

Brian R. C. Kennedy

kennedyb@bu.edu

Randi D. Rotjan

rrotjan@bu.edu

Specialty section:

This article was submitted to Deep-Sea Environments and Ecology,

a section of the journal

Frontiers in Marine Science

Received: 18 November 2019 Accepted: 23 December 2019

Published: 18 February 2020

Citation:

Kennedy BRC, Cantwell K, Malik M,

Kelley C, Potter J, Elliott $K$,

Lobecker E, Gray LM, Sowers D,

White MP, France SC, Auscavitch S,

Mah C, Moriwake V, Bingo SRD,

Putts M and Rotjan RD (2020)

Corrigendum: The Unknown and the Unexplored: Insights Into the Pacific

Deep-Sea Following NOAA

CAPSTONE Expeditions.

Front. Mar. Sci. 6:827.

doi: 10.3389/fmars.2019.00827

\begin{abstract}
Brian R. C. Kennedy ${ }^{1,2 *}$, Kasey Cantwell ${ }^{2,3}$, Mashkoor Malik ${ }^{2}$, Christopher Kelley ${ }^{2,4}$, Jeremy Potter ${ }^{5}$, Kelley Elliott ${ }^{2}$, Elizabeth Lobecker ${ }^{2,6}$, Lindsay McKenna Gray ${ }^{2,7}$, Derek Sowers ${ }^{2,6}$, Michael P. White ${ }^{2,6}$, Scott C. France ${ }^{8}$, Steven Auscavitch ${ }^{9}$, Christopher Mah ${ }^{10}$, Virginia Moriwake ${ }^{4}$, Sarah R. D. Bingo ${ }^{4}$, Meagan Putts ${ }^{4}$ and Randi D. Rotjan ${ }^{1 *}$

${ }^{1}$ Department of Biology, Boston University, Boston, MA, United States, ${ }^{2}$ NOAA Office of Ocean Exploration and Research, Silver Spring, MD, United States, ${ }^{3}$ MAXIMUS, Metro Center, Reston, VA, United States, ${ }^{4}$ University of Hawai'i at Manoa Joint Institute of Marine and Atmospheric Research (JIMAR), Honolulu, HI, United States, ${ }^{5}$ Bureau of Ocean Energy Management, Camarillo, CA, United States, ${ }^{6}$ Cherokee Nation Strategic Programs, Richmond Hwy Suite, Arlington, TX, United States, ${ }^{7}$ Athenium Analytics, Dover, DE. United States, ${ }^{8}$ Department of Biology, University of Louisiana at Lafayette, Lafayette, LA, United States, ${ }^{9}$ Department of Biology, Temple University, Philadelphia, PA, United States, ${ }^{10}$ Department of Invertebrate Zoology, National Museum of Natural History, Smithsonian Institution, Washington, DC, United States
\end{abstract}

Keywords: ocean exploration, multibeam mapping, biodiversity, seamounts, Okeanos Explorer, Anthozoa, Porifera, Echinodermata

\section{A Corrigendum on}

The Unknown and the Unexplored: Insights Into the Pacific Deep-Sea Following NOAA CAPSTONE Expeditions

by Kennedy, B. R. C., Cantwell, K., Malik, M., Kelley, C., Potter, J., Elliott, K., et al. (2019). Front. Mar. Sci. 6:480. doi: 10.3389/fmars.2019.00480

In the original article, there were three typographical errors. The number of hours of ROV video collected was incorrectly listed as 189 in two places in the article when it should have been 891.5 hours. These two typos were in the text only. All figures, effort correction calculations and conclusions were based on the correct number. There was a third, additional error in Table 2: Howland Island and Baker Island were listed as being a PRINMS when in fact it should have read PRIMNM.

A correction has been made to the abstract.

Corrected paragraph: Over a 3-year period, the National Oceanic and Atmospheric Administration (NOAA) organized and implemented a Pacific-wide field campaign entitled CAPSTONE: Campaign to Address Pacific monument Science, Technology, and Ocean NEeds. Under the auspices of CAPSTONE, NOAA mapped 597,230 $\mathrm{km}^{2}$ of the Pacific seafloor (with $61 \%$ of mapped area located within US waters), including 323 seamounts, conducted $187 \mathrm{ROV}$ dives totaling $891.5 \mathrm{~h}$ of ROV benthic imaging time, and documented $>347,000$ individual organisms. This comprehensive effort yielded dramatic insight into differences in biodiversity across depths, regions, and features, at multiple taxonomic scales. For all deep sea taxonomic groups large enough to be visualized with the ROV, we found that fewer than $20 \%$ of the species were able to be identified. The most abundant and highest diversity taxa across the dataset were from three phyla (Cnidaria, Porifera, and Echinodermata). We further examined these phyla for taxonomic assemblage patterns by depth, geographic region, and geologic feature. Within each taxa, there were multiple genera with specific distribution and abundance by depth, region, and feature. Additionally, we observed 
TABLE 2 | CAPSTONE multibeam mapping accomplishments after 3 years of effort by the Okeanos Explorer.

\begin{tabular}{|c|c|c|c|c|c|}
\hline Location & $\begin{array}{c}\text { Total area } \\
\left(\mathbf{k m}^{2}\right)\end{array}$ & $\begin{array}{l}\text { Total mapped after } \\
\text { CAPSTONE }\left(\mathbf{k m}^{2}\right)\end{array}$ & $\begin{array}{c}\% \text { Area mapped after } \\
\text { CAPSTONE }\end{array}$ & $\begin{array}{l}\text { Area mapped by } \\
\text { CAPSTONE }\left(\mathrm{km}^{2}\right)\end{array}$ & $\begin{array}{l}\% \text { Area mapped } \\
\text { by CAPSTONE }\end{array}$ \\
\hline Pacific Ocean & $161,760,000$ & $22,299,018$ & 13.78 & 597,230 & 0.37 \\
\hline Papahanaumokuakea MNM & $1,508,874$ & 578,008 & 38.31 & 94,157 & 6.24 \\
\hline Johnston Atoll PRIMNM & 442,443 & 122,804 & 27.76 & $62,482.4$ & 14.12 \\
\hline Wake Island PRIMNM & 406,970 & 111,580 & 27.42 & 53,259 & 13.09 \\
\hline Marianas Trench MNM & 204,543 & 167,129 & 81.71 & 21,611 & 10.57 \\
\hline Phoenix Islands Protected Area & 406,801 & 68,020 & 16.72 & 19,196 & 4.72 \\
\hline $\begin{array}{l}\text { NMS of American Samoa (Muliava } \\
\text { Sanctuary Unit/Rose Atoll MNM) }\end{array}$ & 34,934 & 16,216 & 46.42 & $1,1955.4$ & 34.22 \\
\hline Jarvis Island PRIMNM & 315,339 & 58,889 & 18.67 & 11,911 & 3.78 \\
\hline NZ Territory of Tokelau & 318,507 & 79,874 & 25.08 & $10,604.2$ & 3.33 \\
\hline Howland Island and Baker Island PRIMNM & 51,149 & 15,041 & 29.41 & $6,356.38$ & 12.43 \\
\hline Kingman Reef and Palmyra Atoll PRIMNM & 53,175 & 46,665 & 87.76 & $5,379.92$ & 10.12 \\
\hline Marae Moana (proposed) & $1,961,280$ & 344,043 & 17.54 & $3,776.59$ & 0.19 \\
\hline Swains Island Sanctuary Unit & 135 & 135 & 99.61 & $11,2.645$ & 83.22 \\
\hline
\end{tabular}

CAPSTONE expeditions resulted in $597,230 \mathrm{~km}^{2}$ area mapped for the entire Pacific Ocean (first row) and all marine protected areas depicted in $\mathrm{km}^{2}$.

multiple genera with broad abundance and distribution, which may focus future ecological research efforts. Novel taxa, records, and behaviors were observed, suggestive of many new types of species interactions, drivers of community composition, and overall diversity patterns. To date, only $13.8 \%$ of the Pacific has been mapped using modern methods. Despite the incredible amount of new known and unknown information about the Pacific deep-sea, CAPSTONE is far from the culminating experience the name suggests. Rather, it marks the beginning of a new era for exploration that will offer extensive opportunities via mapping, technology, analysis, and insights.

A correction has been made to the Discussion, Paragraph 14 (last paragraph):

Ironically named, CAPSTONE is more of a beginning than a culminating experience. It is the launch of decades of data-mining, visual analyses, hypothesis-generation, and justification for future exploration. The trends highlighted in this paper offer a snapshot of what is known, and what remains unknown, in the Pacific Ocean. What we have learned from 3 years and $891.5 \mathrm{~h}$ on the seafloor is that the Pacific is not just a place of historical exploration and voyaging: it is a place that offers extensive opportunities for technology innovations, and insights. In other words, it is a place for future discovery.

Additionally, there was a mistake in Table 2. Row 11 should read Howland Island and Baker Island PRIMNM. The corrected Table 2 appears above.

The authors apologize for these errors and state that these changes do not alter the scientific conclusions of the article in any way. The original article has been updated.

Copyright () 2020 Kennedy, Cantwell, Malik, Kelley, Potter, Elliott, Lobecker, Gray, Sowers, White, France, Auscavitch, Mah, Moriwake, Bingo, Putts and Rotjan. This is an open-access article distributed under the terms of the Creative Commons Attribution License (CC BY). The use, distribution or reproduction in other forums is permitted, provided the original author(s) and the copyright owner(s) are credited and that the original publication in this journal is cited, in accordance with accepted academic practice. No use, distribution or reproduction is permitted which does not comply with these terms. 